\title{
Rectal Medullary Carcinoma
}

National Cancer Institute

\section{Source}

National Cancer Institute. Rectal Medullary Carcinoma. NCI Thesaurus. Code C60640.

A rare, invasive rectal adenocarcinoma characterized by the presence of sheets of

malignant epithelial cells with vesicular nuclei, prominent nucleoli, and abundant eosinophilic cytoplasm. It usually has a favorable prognosis. 